\title{
Development and evaluation of a follow up assessment of preterm infants at 5 years of age
}

\author{
M J K de Kleine, A L den Ouden, L A A Kollée, M W G Nijhuis-van der Sanden, \\ $M$ Sondaar, B J M van Kessel-Feddema, S Knuijt, A L van Baar, A Ilsen, \\ R Breur-Pieterse, J M Briët, R Brand, S P Verloove-Vanhorick
}

Arch Dis Child 2003;88:870-875

See end of article for authors' affiliations

Correspondence to Dr MJK de Kleine, Department of

Neonatology, Máxima Medical Centre, PO Box 7777, $5500 \mathrm{MB}$

Veldhoven, Netherlands:

m.dekleine@pg.tno.nl

Accepted 6 April 2003

\begin{abstract}
Background: Long term follow up shows a high frequency of developmental disturbances in preterm survivors of neonatal intensive care formerly considered non-disabled.

Aims: To develop and validate an assessment tool that can help paediatricians to identify before 6 years of age which survivors have developmental disturbances that may interfere with normal education and normal life.

Methods: A total of 431 very premature infants, mean gestational age 30.2 weeks, mean birth weight $1276 \mathrm{~g}$, were studied at age 5 years. Children with severe handicaps were excluded. The percentage of children with a correctly identified developmental disturbance in the domains cognition, speech and language development, neuromotor development, and behaviour were determined.

Results: The follow up instrument classified $67 \%$ as optimal and $33 \%$ as at risk or abnormal. Of the children classified as at risk or abnormal, $60 \%$ had not been identified at earlier follow up assessments. The combined set of standardised tests identified a further $30 \%$ with mild motor, cognitive, or behavioural disturbances. The paediatrician's assessment had a specificity of $88 \%$ (95\% Cl 83-93\%), a sensitivity of $48 \%(95 \% \mathrm{Cl} 42-58 \%)$, a positive predictive value of $85 \%(95 \% \mathrm{Cl} 78-91 \%)$, and a negative predictive value of $55 \%(95 \% \mathrm{Cl} 49-61 \%)$.

Conclusions: Even after standardised and thorough assessment, paediatricians may overlook impairments for cognitive, motor, and behavioural development. Long term follow up studies that do not include detailed standardised tests for multiple domains, especially fine motor domain, may underestimate developmental problems.
\end{abstract}

S urvival of very preterm and very low birth weight (VLBW) live born infants has increased substantially in the 1980s and the 1990s, with some variation depending on the population investigated and mortality definition used. ${ }^{1-6}$ Developmental outcome varies even more depending on the age of the child at assessment, the population studied, and the definition of handicap used. Follow up during the first two years of life shows the presence of chronic illnesses, especially chronic lung disease, and handicaps such as cerebral palsy and severe developmental delay in $10-20 \%{ }^{78}$ Long term follow up to school age reveals an even higher frequency of developmental impairments. These include motor performance problems, visual and auditory impairments, problems in cognitive and behavioural development, and school failure. ${ }^{9-14}$ In a nationwide follow up of VLBW infants in the Netherlands, the need for special education increased from $19 \%$ at age 9 to $28 \%$ at age 14 years. ${ }^{11}$ Similar figures have been reported from Florida and Cleveland..$^{15}$

At the moment of hospital discharge, the prediction of the long term outcome of individual infants is difficult and not accurate. By the age of 2 years major handicaps such as gross motor disturbances, severe mental retardation, and chronic illnesses will have become clear. Diagnosis of learning disabilities, problem behaviour, and mild motor problems, however, is often delayed until school age. Therefore, long term longitudinal follow up of these children is necessary. Such follow up programmes should aim at the early detection of any developmental disturbances that necessitates developmental intervention as well as at the evaluation of perinatal treatment. A third goal is to contribute to the scientific knowledge of pathways by which specific types of damage in the perinatal period lead to developmental problems in childhood or even in adulthood and to recognise, at an earlier age, factors that predict developmental problems at a later age.

In the Netherlands the majority of very preterm infants are treated in one of 10 perinatal intensive care centres. After treatment, survivors are referred to their local hospital for the remaining neonatal admission and post-discharge care. In the first years after birth they return a number of times to the centre of initial treatment for follow up assessments. Though treatment is similar in the 10 perinatal centres, the follow up programmes are not standardised and post-neonatal care may differ throughout the country. Furthermore, because of a shortage in perinatal care the developmental departments are constantly urged to restrict follow up programmes to the bare minimum. Therefore a national working party on neonatal follow up designed a standardised follow up programme that would offer post-neonatal care as well as standardised follow up figures for all very preterm infants in the Netherlands.

In this paper we present the development of a paediatrician's assessment for the most important developmental domains at 5 years of age and the validation of this assessment against a set of standardised tests. This assessment should help paediatricians to identify, before the age of 6 years, which survivors of neonatal intensive care have developmental disturbances that may interfere with normal education and normal life.

Abbreviations: $\mathrm{CBCL}$, Child Behavior CheckList; DDST, Denver Development Screening Test; ENT, ear, nose, and throat; NICU, neonatal intensive care units; TOMI, test of motor impairment; VLBW, very low birth weight 


\section{POPULATION AND METHODS Study population}

The study population included 5 year old survivors born before 32 weeks of gestation or weighing less than $1500 \mathrm{~g}$ and treated in one of three Dutch neonatal intensive care units (NICUs). For logistic reasons the inclusion periods varied slightly: from l October 1992 to 15 June 1994 in the University Medical Centre Nijmegen (UMCN), from 15 November 1992 to 1 January 1994 in the Academic Medical Centre Amsterdam (AMC), and from 1 January 1993 to 1 January 1995 in the Máxima Medical Centre Veldhoven (MMC). During these time periods 764 infants were consecutively admitted to the three NICUs. One hundred and thirty one (17\%) died before the age of 5 years; and 46 patients below 30 weeks gestation and treated in the AMC were excluded because they participated in another study. ${ }^{17}$ Twenty one children with known severe cerebral palsy, blindness, severe mental retardation, chromosomal abnormalities, or inborn error of metabolism were excluded, because it was obvious that they would not be able to perform the tests. As a result, 566 children were eligible for the study. Perinatal data were prospectively collected during admission, stored in the NICU based databases, and retrospectively retrieved for data analysis.

\section{Paediatrician's assessment}

The paediatrician's assessment at 5 years consisted of a questionnaire sent to the parents and a structured assessment by a paediatrician, specially trained for this purpose.

The questionnaire addressed the following domains: social economic status, general health, visual and auditory function, motor development, cognitive development, language and behaviour. Social status of the child was assessed by questions about residence, upbringing, and number of siblings, and by questions about employment and education of both parents. General health was assessed by questions about medical consumption (visits to outpatient clinic, number of hospital admissions, number of operations, number of diagnostic tests), somatic symptoms of the ear, nose, and throat (ENT), respiratory, gastrointestinal, and central nervous systems, and the use of medicines. Visual and auditory functions were assessed by questions about hearing without or with hearing aids and vision without or with glasses. Cognitive development was assessed by questions about school performance, including learning problems and the need for remedial teaching or special school. Problem behaviour was addressed by a shortlist of those 15 problem items from the Child Behavior CheckList (CBCL), that discriminated most between normal children and children referred to mental health services in the general population. ${ }^{18}$

The paediatrician's assessment started with a check and further exploration of the data from the questionnaire, measurement of growth parameters, and blood pressure. This was followed by a formal physical examination.

Neurological function was assessed according to Touwen. ${ }^{19}$ This assessment consists of 40 items that cover tone, reflexes, muscle power, involuntary movements, posture, balance, coordination, and gross motor skills. The children were assigned to the following categories: normal (no neurological abnormalities), minor neurological dysfunction (neurological abnormalities without influence on normal posture or movement), or cerebral palsy (neurological abnormalities with abnormal posture or movements).

The Denver Development Screening Test (DDST) was used to assess neuromotor and cognitive functioning..$^{20}$ The DDST consists of 105 test items, clustered into four groups: motor function, language, adaptation, and social behaviour. Each test item has a cut off point at an age that $90 \%$ of Dutch children are able to perform it. ${ }^{20}$ A child was classified as abnormal when he scored two or more delays beyond the cut off point in each of two groups, or two delays in one group plus one delay in another group without compensation in the same group. He scored at risk when he scored two or more delays in one group or one delay in a group without compensation in the same group. In all other cases he scored normal.

Language was assessed by an age appropriate Dutch Language Screening Test, designed and validated by Gerritsen. ${ }^{21}$ This test consists of 39 items covering the use of vocabulary, comprehension, memory and production of language, use of plurals and prepositions, and pronunciation. Normal score is equal or less than 17, at risk ranges from 18 to 25 and abnormal from 25 to the maximal score of 52 .

The results were summarised into five domains: cognitive development, neuromotor development, language development, behaviour and general health, and a final conclusion: (1) all domains normal, "optimal"; (2) further examination necessary, "at risk"; or (3) treatment necessary or already treated in one or more domains, "abnormal".

\section{Validation instruments}

The combined results of the paediatrician's assessment were validated against a combined set of standardised tests for cognitive, motor, and language development. This set consisted of the revised Amsterdam child intelligence test (IQ test), ${ }^{22}$ the Movement Assessment Battery for Children (movement $\mathrm{ABC}),{ }^{23}$ and the full Child Behavior CheckList (CBCL) ${ }^{24}{ }^{25}$ Trained child psychologists and child physiotherapists performed these tests. They were blinded to the findings of the paediatrician's assessment. The IQ test took one hour, the movement $\mathrm{ABC}, 45$ minutes.

The revised Amsterdam child intelligence test has been normalised for Dutch children between 4 and 7 years of age. Children with a score between -2 and -1 standard deviations were considered at risk, those below 2 standard deviations were abnormal.

The movement $\mathrm{ABC}$ indicates motor functioning in daily life. ${ }^{23}$ Normative data have been collected in the USA, UK, and the Netherlands and yielded similar cut off points for normal American and Dutch children. ${ }^{23}{ }^{26}$ Total scores below or equal to 10.5 (15th centile) were considered normal, from 11.0 to 17.0 (5th centile) at risk, and above 17.0 abnormal.

The CBCL is a standardised measure of child behaviour, developed by Achenbach and normalised for Dutch children by Verhulst. ${ }^{25}{ }^{27}$ Total scores up to and including 59 are considered normal, from 60 up to and including 63 intermediate, and from 64 upwards "clinically important" disturbance of behaviour.

When all tests gave a normal result the final conclusion was "optimal"; when the results of one or more of the three tests was "at risk" or "abnormal", the final conclusion was "at risk" or "abnormal" respectively.

\section{Statistical analysis}

Differences of continuous perinatal risk factors between groups were compared with the Student's $t$ test, and differences between dichotomous risk factor with the $\chi^{2}$ test; $\mathrm{p}$ values $<0.05$ were considered statistically significant. Comparison of the paediatrician's assessment with the formal assessments was expressed as sensitivity, specificity, and percentage correctly classified. Since no arbitrary cut off points were involved and classification into normal or abnormal was fixed by the test definition, ROC curves did not apply. Positive and negative predicted values, likelihood ratios, and post-test probabilities estimated the performance of the test in practice.

\section{RESULTS}

Of the 566 eligible children, 135 (23.9\%) were not assessed for various reasons (table 1), but language problems played an important role. Non-response rate was 65\% (36/55) in children of non-Dutch and 19\% (99/511) of Dutch speaking families $(p=0.000)$. Of the 431 tested children, 395 
Table 1 Eligible and assessed patients

\begin{tabular}{lrrrr}
\hline & $\mathrm{n}$ & $\%$ & $\mathrm{n}$ & $\%$ \\
\hline Cohort 1992-94 & 764 & 100 & & \\
Died & 131 & 17.2 & & \\
Excluded because of participation in another study & 46 & 6.0 & & \\
Excluded because of severe handicap & 21 & 2.8 & & \\
Eligible & 566 & 74 & 566 & 100 \\
$\quad$ Not assessed & & & 30 & 5.3 \\
$\quad$ Address unknown & & & 7 & 1.2 \\
$\quad$ Moved outside the country & & & 52 & 9.2 \\
Impossibility to make a convenient appointment & & 431 & 76.2 \\
$\quad$ Refusal by the parents & & & \\
Assessed & & & \\
\hline
\end{tabular}

Table 2 Risk factors in the study group and the non-response group

\begin{tabular}{llll}
\hline & $\begin{array}{l}\text { Assessed } \\
(n=431)\end{array}$ & $\begin{array}{l}\text { Not assessed } \\
(n=135)\end{array}$ & p value \\
\hline Male & $55 \%$ & $49 \%$ & 0.001 \\
Multiple births & $36 \%$ & $21 \%$ & \\
Congenital malformations & $10 \%$ & $7 \%$ & \\
Gestational age, weeks (SD) & $30.2(2.0)$ & $30.1(1.9)$ & \\
Birth weight, g (SD) & $1276(332)$ & $1327(321)$ & \\
& & & \\
Caesarean section & $48 \%$ & $47 \%$ & \\
Apgar score at 5' $<7$ (n=565) & $17 \%$ & $14 \%$ & \\
Resuscitation including endotracheal ventilation & $24 \%$ & $28 \%$ & \\
& & $49 \%$ & \\
Positive pressure ventilation & $49 \%$ & $18 \%$ & \\
Surfactant administration & $19 \%$ & $26 \%$ \\
Bronchopulmonary dysplasia & $14 \%$ & $32(28)$ & \\
Intraventricular haemorrhage, grade 1-4 & $19 \%$ & & \\
Days in NICU (SD) & $32(31)$ & & \\
\hline
\end{tabular}

Table 3 Results of the separate tests

\begin{tabular}{lcccc}
\hline & $\begin{array}{l}\text { Paediatrician's } \\
\text { assessment }\end{array}$ & $\begin{array}{l}\text { Movement } \\
\text { ABC }\end{array}$ & IQ test & CBCL \\
\hline Number assessed per test & 412 & 404 & 402 & 407 \\
Optimal & $275(67 \%)$ & $228(56 \%)$ & $319(78 \%)$ & $314(77 \%)$ \\
At risk & $58(14 \%)$ & $86(21 \%)$ & $63(16 \%)$ & $37(9 \%)$ \\
Abnormal & $79(19 \%)$ & $90(22 \%)$ & $25(6 \%)$ & $56(14 \%)$ \\
\hline
\end{tabular}

completed all the batteries of the paediatrician's assessment, IQ test, movement ABC, and CBCL. The exact number of children that completed each test is included in the tables.

Mean gestational age (30.2 (SD 2.0) weeks) and mean birth weight (1267 (SD 332) g) were relatively high compared to most follow up studies from the 1990s. This illustrates the selection bias caused by non-inclusion of infants with gestational ages below 30 weeks from one of the three participating hospitals. There were no differences in perinatal data between assessed and non-assessed children, with the exception of multiple births (36\% of the assessed versus $21 \%$ of the non-assessed children; table 2).

In 412 children a full paediatrician's assessment was performed. The total assessment took approximately one hour and could be performed in a routine outpatient setting. The paediatricians involved felt it contributed highly to their ability to assess development in preschool children. Most children liked the different parts of the assessment and their parents were very satisfied with the thorough examination. The assessment resulted in $275(67 \%)$ children classified as optimal, 58 (14\%) as at risk, and 79 (19\%) as abnormal. Of the 137 children classified as at risk or abnormal, $82(60 \%)$ had not been identified at earlier follow up assessments.

The IQ test classified $56 \%$ of the children as optimal and $24 \%$ as non-optimal, the CBCL $77 \%$ and $23 \%$. The movement $\mathrm{ABC}$, however, indicated $43 \%$ of the children with a motor problem (table 3 ). The combined results of the three formal assessments indicated significantly more children with developmental disturbances than the paediatrician's assessment. Only 167 children (42\%) scored optimal; 228 (58\%) were identified as at risk or abnormal by at least one of the tests (table 4).

The specificity ( $88 \%$ ) and positive predictive value (85\%) of the paediatrician's assessment were adequate, but many children with a developmental disturbance were not identified by it, resulting in a sensitivity of $48 \%$ and a negative predictive value of $55 \%$ (table 4 ).

Further investigation of the 20 children classified as abnormal or at risk by the paediatrician's assessment but not by any of the validated tests showed that 10 had delayed language 


\begin{tabular}{|c|c|c|c|}
\hline \multirow{2}{*}{$\begin{array}{l}\text { Conclusion of } \\
\text { paediatrician's } \\
\text { assessment }\end{array}$} & \multicolumn{3}{|c|}{$\begin{array}{l}\text { Conclusion of the combined set o } \\
\text { standardised tests }\end{array}$} \\
\hline & $\begin{array}{l}\text { At risk or } \\
\text { abnormal }\end{array}$ & Optimal & All \\
\hline At risk or abnormal & 110 & 20 & 130 \\
\hline Optimal & 118 & 147 & 265 \\
\hline \multirow[t]{2}{*}{ All } & 228 & 167 & 395 \\
\hline & & \multicolumn{2}{|l|}{$95 \% \mathrm{Cl}$} \\
\hline Sensitivity & $48 \%$ & \multirow{4}{*}{\multicolumn{2}{|c|}{$\begin{array}{l}42-55 \% \\
83-93 \% \\
78-91 \% \\
49-61 \%\end{array}$}} \\
\hline Specificity & $88 \%$ & & \\
\hline Positive predictive value & $85 \%$ & & \\
\hline Negative predictive value & $55 \%$ & & \\
\hline \multicolumn{4}{|l|}{ Prior probability } \\
\hline Pretest odds & \multicolumn{3}{|l|}{1.4} \\
\hline \multicolumn{4}{|l|}{ Positive test } \\
\hline Positive likelihood ratio & 4.03 & \multicolumn{2}{|l|}{$2.61-6.21$} \\
\hline Post-test probability & 0.85 & \multicolumn{2}{|l|}{$0.78-0.89$} \\
\hline Post-test odds & 5.5 & & \\
\hline \multicolumn{4}{|l|}{ Negative test } \\
\hline Negative likelihood ratio & 0.59 & \multicolumn{2}{|l|}{$0.51-0.67$} \\
\hline Post-test probability & 0.45 & \multicolumn{2}{|l|}{$0.41-0.48$} \\
\hline Post-test odds & 0.8 & & \\
\hline
\end{tabular}

development according to the DDST or the language screening test, in two of them combined with either behaviour or cognitive problems. Three children had an abnormal neurological assessment and four showed abnormal behaviour during the assessment. Three of these children were suspected of a nonoptimal cognitive development while their IQs proved to be 89 , 95, and 97, respectively. Two children were considered as not optimal without further specification.

Of the 118 children that were incorrectly not identified by the paediatrician's assessment, the majority failed on the movement ABC: 54 scored between the P5 and P15, and 25 below the P5. In 24 of them either behaviour problems or cognitive delay or both accompanied this. One third $(n=43)$ had a high total problem score on the CBCL, of whom 10 also had other problems. Nineteen children proved to have an IQ score of one SD or more below the mean, also mostly in combination with other problems.

Fifty four children had an abnormal outcome on both the paediatrician's assessment and the validated tests. One third of them (18/54) were not identified before the follow up appointment and did not receive any intervention therapy. Furthermore, multiple problems did not enhance earlier recognition or intervention. Sixty five per cent (55/85) of the children with a failure on more than one test were not identified previously.

\section{DISCUSSION}

Follow up of the first survivors of modern neonatal care, that started in the 1970s, showed that preterm birth has an effect well into adulthood. ${ }^{28}$ Advances in neonatal care since the early days have led to an increase of survival. Developmental sequelae, however, are still a major problem, mostly because babies who would previously have been expected to die are now surviving neonatal intensive care. ${ }^{82}$ Follow up studies have shown that developmental problems increase with age, and seemingly healthy toddlers may still have developmental problems and school failure at a later age. ${ }^{3031}$ This makes long term follow up mandatory, both for timely identification of children in need of extra help and to enable a true evaluation of neonatal intensive care. There is no consensus about what should be measured at what age. ${ }^{30}{ }^{32}$ As a result, outcomes in different studies are not always comparable. To achieve reliable outcome measurements, it is necessary to include validated and multidisciplinary instruments into follow up programmes that assess different domains of development. However, funding for such intensive programmes is usually deficient. We therefore tried to develop a comprehensive follow up instrument, manageable by a paediatrician, that could differentiate between preschool children with optimal, and with suboptimal or abnormal development. This instrument proved suitable for use in an outpatient clinic, although it takes approximately one hour to assess a 5 year old child. The assessment enabled the participating paediatricians in this study to identify 137 children with developmental problems, of whom $82(60 \%)$ were not identified at earlier assessments.

Studies that succeeded in reaching a virtually $100 \%$ follow up rate have shown that the disability rate in children that are hard to follow up is considerably higher than in children that are easy to follow up. ${ }^{33}$ This selection bias means that the number of children with developmental problems is even higher.

The specificity of the assessment was quite high, $88 \%$. Only 20 children were assessed "false positive". Ten of them were considered to be at risk, and three abnormal because of language or behavioural problems and therefore regarded as not optimal. This means that using this instrument as a screening instrument, unnecessary referral for full assessment will be infrequent.

However, only half of the children with abnormal results on one or more of the standard assessments were identified by the paediatrician's assessment. The majority of them had either motor problems or behaviour problems or a combination; a minority failed on the IQ test. It could be argued that developmental disturbances that do not give rise to suspicion at school or at home and are not identified by a standardised and thorough paediatrician's assessment are not important. On the other hand many of these children encountered delays in more than one domain. Mild impairments at the age of 5 are often not disabling at that age and would perhaps not be insuperable when occurring alone. The combination of problems, however, robs these children from the potential to compensate and puts them at risk for later learning disabilities and social isolation. Some of them may even become more disabled than their peers with a single, but more severe impairment.

Some studies underlined a relation between motor dysfunction at an early age and cognitive problems at school age and later, ${ }^{34-38}$ although other studies did not. ${ }^{39}$ The failure to recognise motor disturbances at an early age may be one of the reasons for the seemingly increase in developmental problems with increasing age. On the test of motor impairment (TOMI), the predecessor of the movement ABC used in our study, Powls et al reported an improvement of motor function in half of the assessed preterm children between the ages of 6 and 8 years. However, at age 12 the percentage of school problems was 34 in children who failed on the TOMI at age 6 versus $5 \%$ of the children with optimal results. ${ }^{40}$

Motor disturbances that predict later developmental problems may be found at a much earlier age. ${ }^{38}{ }^{41}$ Hadders-Algra and Groothuis reported an association between mildly abnormal general movements at fidgety age (2-4 months postterm) and the development of attention problems and minor neurological dysfunction at the age of 4-9 years. ${ }^{38}{ }^{41}$ They hypothesised that perinatal hypoxia had resulted in long term changes in the striatic dopaminergic system. These disturbances could have influenced motor fluency and coordination in early childhood and behaviour in later life.

Motor performance is a result of information processing. The more task complexity increases, the more the information 
processing becomes important. As the movement $\mathrm{ABC}$ tests more than only motor domain, it is, in all likelihood, a good detector of the information processing capacity of the nervous system. We therefore assume that a high impairment score in the movement $\mathrm{ABC}$ tests does not only indicate a motor problem, but also identifies children who are at risk for developmental problems in other domains. By inclusion of the movement $\mathrm{ABC}$ in the paediatrician's assessment, only six children with cognitive delay would have been missed erroneously, five with IQ scores between -2 and -1 standard deviations and one below 2 standard deviations. Therefore we propose to include the movement ABC in the paediatrician's assessment at age 5, and also base the need for further assessment on the results of this test.

Children of non-Dutch speaking families were far more likely not to participate in the assessment than their Dutch peers (65\% versus 19\%). The majority of these families belonged to a low socioeconomic class, had low educational levels, and experienced cultural barriers when they looked for medical help. Moreover, an insufficient test result in children of non-Dutch speaking families was in some cases interpreted as a linguistic problem and not as a cognitive problem. Sometimes this interpretation was correct, sometimes it was not. As a result, the tests were often inconclusive in this population. Preterm children in these families are therefore threatened by a combination of biological and social risk factors that may cause long delays before they get the interventions they need.

In conclusion, the systematic and standardised paediatrician's assessment at age 5 years did identify a significant number of children in whom the need for intervention was not recognised by the standard care they received. We also found that inclusion of the movement $\mathrm{ABC}$ might be necessary to avoid underestimation of a large number of developmental problems. Non-native children were seldom assessed properly.

Long term follow up studies of adolescents and young adults who were born preterm show that a developmental problem may pose a lifelong burden. Neonatal follow up should therefore aim to identify such problems at an early age and provide intervention therapy when needed. Furthermore, the evaluation of perinatal care should include late sequelae. Early predictors of these late sequelae are necessary in the research aimed at advancing perinatal care. We proved this could only be done with an extensive multidisciplinary assessment. Follow up studies that do not include detailed, standardised tests for several domains will underestimate developmental problems in survivors of neonatal intensive care and may be the reason for incomparability of follow up results and a seemingly increase of developmental problems at later ages. Our study indicates that there is no simple way to identify children in need of extra help or to give a true evaluation of neonatal intensive care.

\section{ACKNOWLEDGEMENTS}

The authors thank Ina Kloosterman-Boerrigter, Jan Buijs, Karin Koldewijn, and Marion Wit for their participation in the Validation Study Group, and Astrid Ehrnreich, Lili Jung, Brigit Hamers, and Elle van de Bogaart for their help in studying the children. The authors thank Professor Dr M Hadders-Algra for her help in setting up this study and training the paediatricians and Professor Dr MJ Jongmans for her comments on the study and the manuscript. The study was supported by a grant of the Dutch Health Organisations Praeventiefonds, project number 28-2756, and ZorgOnderzoek Nederland (ZON), project number 1010004-20.

\section{Authors' affiliations}

M J K de Kleine, Department of Neonatology, Máxima Medical Centre, Veldhoven, Netherlands

A L den Ouden, TNO Prevention and Health, Leiden, Netherlands

L A A Kollée, Department of Paediatrics, University Medical Centre,

Nijmegen, Netherlands
M W G Nijhuis-van der Sanden, Department of Child Physiotherapy,

University Medical Centre Nijmegen, Netherlands

M Sondaar, Department of Medical Psychology, University Medical

Centre, Nijmegen, Netherlands

B J M van Kessel-Feddema, Department of Medical Psychology,

University Medical Centre, Nijmegen, Netherlands

S Knuijt, Department of Neurology, University Medical Centre,

Niimegen, Netherlands

A L van Baar, Department of Medical Psychology, Máxima Medical

Centre, Veldhoven and Department of Neonatology, Academic Medical

Centre, Amsterdam, Netherlands

A Ilsen, R Breur-Pieterse, J M Briët, Department of Neonatology,

Academic Medical Centre, Amsterdam, Netherlands

R Brand, Department of Medical Statistics, Leiden University Medical

Centre, Netherlands

S P Verloove-Vanhorick, TNO Prevention and Health, Leiden, and

Professor of Child Health, Leiden University Medical Centre, Netherlands

\section{REFERENCES}

1 Richardson DK, Gray JE, Gortmaker SL, et al. Declining severity adjusted mortality: evidence of improving neonatal intensive care. Pediatrics 1998;102:893-9.

2 International Neonatal Network, Scottish Neonatal Consultants, Nurses Collaborative Study Group. Risk adjusted and population based studies of the outcome for high risk infants in Scotland and Australia. Arch Dis Child Fetal Neonatal Ed 2000;82:F1 18-23.

3 Battin M, Ling EW, Whitfield MF, et al. Has the outcome for extremely low gestational age (ELGA) infants improved following recent advances in neonatal intensive care? Am J Perinatol 1998;15:469-77.

4 The Victorian Infant Collaborative Study Group. Economic outcome for intensive care of infants of birthweight 500-999 $\mathrm{g}$ born in Victoria in the post surfactant era. J Paediatr Child Health 1997;33:202-8.

5 Verloove-Vanhorick SP, Verwey RA, Brand R, et al. Neonatal mortality risk in relation to gestational age and birthweight. Results of a national survey of preterm and very-low-birthweight infants in the Netherlands. Lancet 1986;1:55-7.

6 Health Council of the Netherlands. Intensive care at birth. Publication no. 2000/08. The Hague: Health Council of the Netherlands, 2000.

7 The Victorian Infant Collaborative Study Group. Outcome at 2 years of children 23-27 weeks' gestation born in Victoria in 1991-92. J Paediatr Child Health 1997;33:161-5.

8 Wood NS, Marlow N, Costeloe K, et al. Neurologic and developmental disability after extremely preterm birth. EPICure Study Group. N Engl J Med 2000:343:378-84

9 Veen S, Ens-Dokkum MH, Schreuder AM, Verloove-Vanhorick SP, et al. Impairments, disabilities, and handicaps of very preterm and very-low-birhtweight infants at five years of age. The collaboration project on preterm and small for gestational age infants (POPS) in the Netherlands. Lancet 1991:338:33-6.

10 The Victorian Infant Collaborative Study Group. Neurosensory outcome at 5 years and extremely low birthweight. Arch Dis Child Fetal Neonatal Ed 1995;73:F143-6.

11 Hille ET, den Ouden AL, Bauer L, et al. School performance at nine years of age in very premature and very low birth weight infants: perinatal risk factors and predictors at five years of age. Collaborative Project on Preterm and Small for Gestational Age (POPS) Infants in The Netherlands. J Pediatr 1994;125:426-34.

12 Vohr BR, Msall ME. Neuropsychological and functional outcomes of very low birth weight infants. Semin Perinatol 1997:21:202-20.

13 Taylor HG, Klein N, Schatschneider C, et al. Predictors of early school age outcomes in very low birth weight children. J Dev Behav Pediatr 1998; 19:235-43

14 Schaap AH, Wolf $\mathrm{H}$, Bruinse HW, et al. School performance and behaviour in extremely preterm growth-retarded infants. Eur J Obstet Gynecol Reprod Biol 1999:86:43-9.

15 Resnick MB, Gomatam SV, Carter RL, et al. Educational disabilities of neonatal intensive care graduates. Pediatrics 1998;102:308-14.

16 Hack M, Flannery DJ, Schluchter $M$, et al. Outcomes in young adulthood for very-low-birth-weight infants. N Engl J Med 2002;346: 149-57.

17 van Wassenaer AG, Kok JH, de Viilder JJ, et al. Effects of thyroxine supplementation on neurologic development in infants born at less than 30 weeks' gestation. N Engl J Med 1997;336:21-6.

18 Verhulst FC, Akkerhuis GW, Althaus M. Mental health in Dutch children: (I). A cross-cultural comparison. Acta Psychiatr Scand Suppl 1985:323: 1-108.

19 Touwen BC. Examination of the child with minor neurological dysfunction. Clinics in Developmental Medicine 1989;11:353-63.

20 Cools ATM, Hermans JMA. Dos-handleiding. Denver Ontwikkeling Screeningstest. Lisse: Swets \& Zeitlinger, 1979

21 Gerritsen FME. VTO Taalscreening 3-tot 6-jarigen: de ontwikkeling van een taalscreeningsinstrument voor gebruik in de Jeugdgezondheidszorg. Amsterdam/Lisse: Swets \& Zeitlinger, 1988

22 Bleichrodt N, Resing WCM, Drenth PJD, et al. Intelligentie-meting bij kinderen: empirische en methodologische verantwoording van de geReviseerde Amsterdamse Kinder Intelligentie Test. Lisse: Swets \& Zeitlinger, 1987.

23 Henderson SE, Sugden DA. The Movement Assessment Battery for Children. San Antonio: Psychological Corporation, 1992.

24 Achenbach TM. Manual for the Child Behavior Checklist/4-18 and 1991 Profile. Burlington, VT: University of Vermont, Department of Psychiatry, 1991. 
25 Verhulst FC, van-der-Ende J, Koot HM. Manual for the Child BehaviorChecklist/4-18 (Dutch version). Rotterdam: Department of Child Psychiatry, Sophia Children's Hospital/Academic Hospital Rotterdam/Erasmus Universiteit Rotterdam, 1996.

26 Smits-Engelsman BCM. Movement ABC; Nederlandse Handleiding [Dutch manual Movement ABC]. Lisse: Swets \& Zeitlinger, 1998.

27 Verhulst FC, Berden GFMG, Sanders-Woudstra JAR. Mental health in Dutch children: (II) the prevalence of psychiatric disorder and relationship between measures. Acta Psychiatr Scand 1985;72:1-45.

28 Steward AL, Rifkin L, Amess PN, et al. Brain structure and neurocognitive and behavioural function in adolescents who were born very preterm. Lancet 1999:353:1653-7.

29 Lorenz JM. Survival of the extremely preterm infant in North America in the 1990s. Clin Perinatol 2000;27:255-62

30 McCormick MC. The outcomes of very low birth weight infants: are we asking the right questions? Pediatrics 1997;99:869-76.

31 Wolke D. Psychological development of prematurely born children. Arch Dis Child 1998;78:567-70.

32 Jobe AH. Predictors of outcomes in preterm infants: which ones and when? J Pediatr 2001;138:153-6.

33 Wariyar UK, Richmond S. Morbidity and preterm delivery; importance of 100\% follow-up. Lancet 1989;1:387-8.
34 Diamond A. Close interrelation of motor development and cognitive development and of the cerebellum and prefrontal cortex. Child Dev 2000;71:44-56.

35 Botting N, Powls A, Cooke RW, et al. Cognitive and educational outcome of very-low-birthweight children in early adolescence. Dev Med Child Neurol 1998;40:652-60.

36 Hadders-Algra $M$, Touwen BC. Minor neurological dysfunction is more closely related to learning difficulties than to behavioral problems. J Learn Disabil 1992;25:649-57.

37 Hadders-Algra $\mathbf{M}$. Two distinct forms of minor neurological dysfunction: perspectives emerging from a review of data of the Groningen Perinatal Project. Dev Med Child Neurol 2002;44:561-71.

38 Gillberg IC, Gillberg C. Children with preschool minor neurodevelopmental disorders. IV: Behaviour and school achievement at age 13. Dev Med Child Neurol 1989:31:3-13.

39 D'Eugenio DB, Slagle TA, Mettelman BB, et al. Developmental outcome of preterm infants with transient neuromotor abnormalities. Am J Dis Child 1993; 147:570-4

40 Powls A, Botting N, Cooke RW, et al. Motor impairment in children 12 to 13 years old with a birthweight of less than $1250 \mathrm{~g}$. Arch Dis Child Fetal Neonatal Ed 1995:73:F62-6.

41 Hadders-Algra M, Groothuis AMC. Quality of general movements in infancy is related to neurological dysfunction, ADHD, and aggressive behavior. Dev Med Child Neurol 1999;41:381-91.

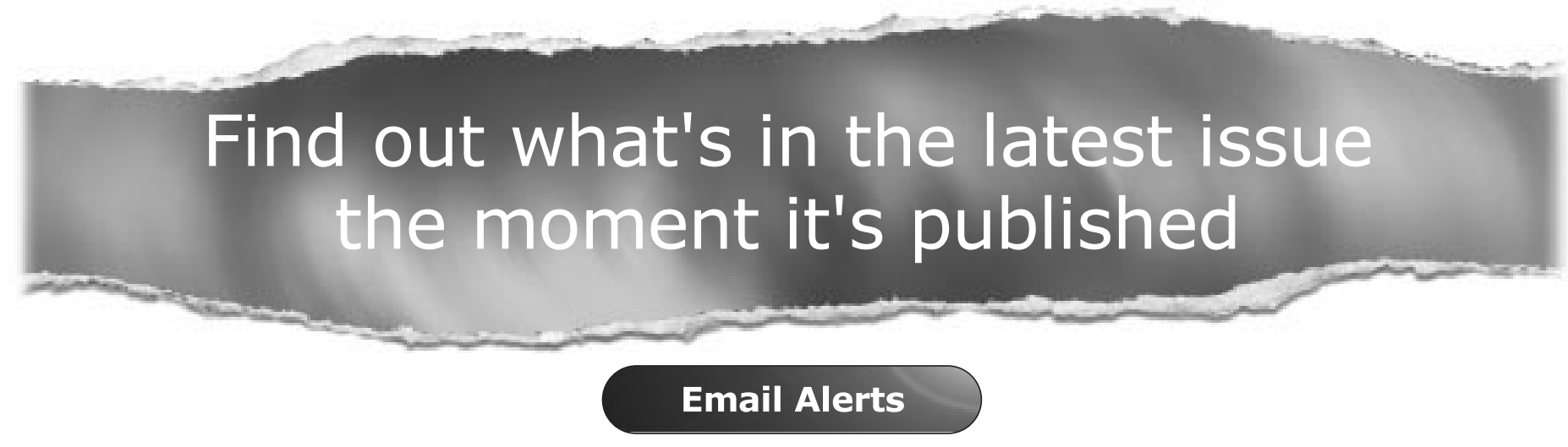

Sign up to receive the table of contents by email every month. You can select from three alerts: Table of Contents (full), TOC Awareness (notice only); Archives of Disease in Childhood related announcements.

www.archdischild.com 